\title{
ВОЗМОЖНОСТЬ ИСПОЛЬЗОВАНИЯ ЮВЕНОИДОВ С МИКРОДОЗАМИ ИНСЕКТИЦИДОВ ДЛЯ ПОВЫШЕНИЯ ЭФФЕКТИВНОСТИ БОРЬБЫ С ТЕПЛИЧНОЙ БЕЛОКРЫЛКОЙ
}

\begin{abstract}
Жесткие санитарно-гигиенические требования резко ограничили ассортимент препаратов, применявшихся в закрытых грунтах против тепличной белокрылки (ТБ). Между тем в случаях массового появления вредителя еще нередко приходится прибегать к химическим средствам защиты, небезопасным для урожая. Именно поэтому необходима дальнейшая разработка новых пестицидов, малотоксичных для позвоночных. $\mathrm{K}$ препаратам такого рода относятся, в частности, регуляторы роста и развития насекомых (ювеноиды, ингибиторы синтеза хитина и т. д.), обладающие высокой избирательностью действия.

Определенный опыт применения ювеноидов против вредных насекомых уже имеется. Рядом зарубежных авторов уже практически подтверждена перспективность кинопрена как ювеноида против ТБ $\left[{ }^{1-3}\right]$. Подобные исследования проводятся и в нашей стране. В частности, в Институте химии АН ЭССР ведется синтез новых ювеноидов оригинальной структуры. Испытания их на ТБ выявили высокую активность эфоксена (АЮГ-80А) [4,5]. В лабораторных опытах этот препарат незначительно уступает по активности лучшим ювеноидам фирмы «Zoecon Comp.» (США). Производственные опыты показали, что своевременная обработка препаратом позволяет подавить нарастание численности вредителя на протяжении месяца. Однако в условиях массового размножения ТБ эффективность действия существующих препаративных форм эфоксена недостаточна.

Нами была предпринята попытка создать более активные против ТБ препаративные формы эфоксена путем введения в их состав незначительных количеств фосфорорганических инсектицидов. В настоящей работе излагаются результаты этсго исследования.
\end{abstract}

\section{Материалы и методы}

Использовали эфоксен в чистом виде и его же с добавками фосфорорганических препаратов - актелика, широко применяемого в борьбе с ТБ, и диазинона, контактного инсектицида кратковременного действия $(5 \%$ по действующему веществу (д. в.)), и сравнивали их по эффективности действия на ТБ. Все препараты синтезированы в Институте химии $\mathrm{AH}$ ЭССР, в каждый из них был введен эмульгатор ОП-7 (13-15\%) и эмульсионные добавки.

В эталонных для каждого варианта препаративных формах эфоксен заменяли нейтральным парафиновым маслом. В контроле проводили обработку препаративной формой без ювеноида и без инсектицида. Препаративные формы испытывали в лабораторных условиях на личинках TБ III-IV возраста, наиболее чувствительных к действию ювеноидов. ТБ выращивали на фасоли. Обработку растений проводили методом окунания листьев с личинками в растворы разной концентрации. Пре- 
паративные формы эфоксена разводили в воде в концентрации $0,3,0,1$, $0,03,0,01 \%$ и т.д. по д. в. Эталонные препараты, где присутствовал только инсектицид, а вместо ювеноида было введено масло, разводили аналогично опытным образцам с ювеноидом.

Оценку эффективности действия препаративных форм проводили через 14-15 дней, когда в контроле заканчивался вылет имаго. Подсчитывали суммарный процент смертности личинок, пупариев и имаго от исходной численности личинок. Гибель личинок происходит в результате токсического действия препаратов, тогда как гибель последующих стадий - пупариев и имаго - наступает в основном из-за нарушения гормонального баланса. Сравнительную оценку активности препаративных форм давали по летальной концентрации, вызывающей гибель $50 \%$ обработанных особей $\left(Л K_{50}, \%\right)$.

\section{Результаты и обсуждение}

Смертность ТБ определяли, применяя каждый препарат в отдельности, а также 2-компонентные смеси в соотношении $20: 1$. Препаративная форма, содержащая только эфоксен без добавления инсектицидов (№ 1), вызывает гибель $50 \%$ особей при рабочей концентрации препарата $0,025 \%$ (табл. 1 и рисунок). Добавление фосфорорганических инсектицидов - диазинона и актелика - повысило эффективность пре-

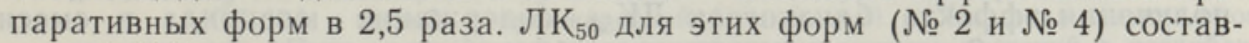
ляет $0,01 \%$. Для эталонных препаративных форм, содержащих только

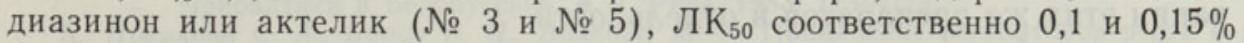
(табл. 1), т. е. в 10 раз больше.

Содержание д. в. в растворах препаративных форм, вызывающих гибель $50 \%$ особей, одинаково в обеих бинарных смесях $-0,0071 \%$, в препаративных формах с одним диазиноном - 0,0036\% и с одним актеликом - 0,0054\%.

Оценку эффективности бинарных смесей проводили исходя из модели независимого действия отдельных компонентов. Показано, что обработка личинок ТБ смесями № 2 и № 4 (табл. 2) вызывает превышение наблюдаемой смертности в 2 раза над уровнем, предсказываемым моделью, т. е. при взаимодействии соединений двух разных типов имеет место синергетический эффект.

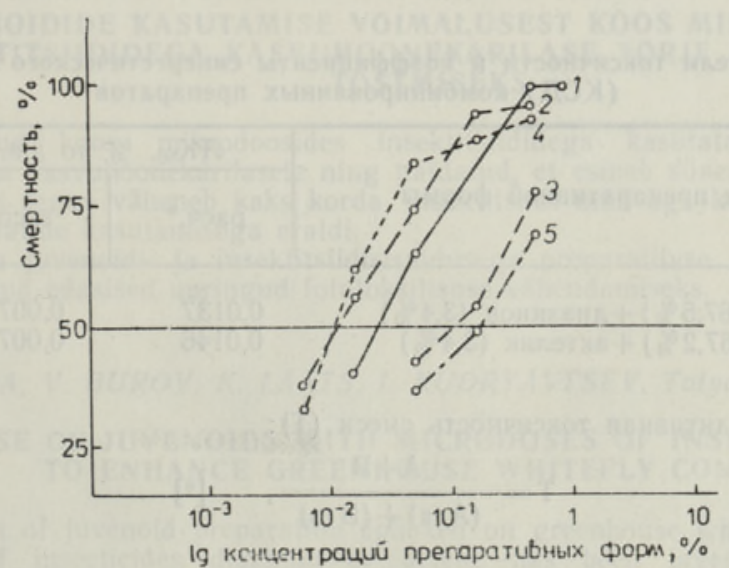

Зависимость гибели личинок тепличной белокрылки (т концентрашии препарата: 1 - эфоксен, 2 - смесь эфоксена и диазинона $(20: 1), 3$ - диазинон, 4 - смесь эфоксена и актелика $(20: 1), 5$ - актелик, 
Дозы препаратов, вызывающие одинаковый эффект при обработке личинок старших возрастов тепличной белокрылки

\begin{tabular}{|c|c|c|c|c|c|}
\hline \multirow{2}{*}{ 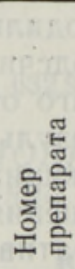 } & \multirow{2}{*}{ Вид препаративной формы } & \multicolumn{2}{|c|}{$\mathrm{JK}_{50}, \%$} & \multicolumn{2}{|c|}{$\begin{array}{c}\text { Содержание активных } \\
\text { веществ в препаратив } \\
\text { ной форме, } \\
\% \text { при ЛК } \\
\end{array}$} \\
\hline & & $\begin{array}{l}\text { по препа- } \\
\text { ративной } \\
\text { форме }\end{array}$ & по д. в. ${ }^{*}$ & эфоксена & $\begin{array}{c}\text { инсекти- } \\
\text { цида }\end{array}$ \\
\hline 1 & Эфоксен $(65,1 \%)$ & 0,025 & 0,01 & 0,016 & \\
\hline$?$ & Эфоксен $(67,5 \%)+$ диазинон $(3,4 \%)$ & 0,01 & 0,0071 & 0,0068 & 0.0003 \\
\hline 7 & $\begin{array}{l}\text { Диазинон }(3,6 \%) \\
\text { Эфоксен }(67,2 \%)+\text { актелик }(3,4 \%)\end{array}$ & 0,01 & $\begin{array}{l}0,0036 \\
0,0071\end{array}$ & $0, \overline{00} 68$ & $\begin{array}{l}0,0036 \\
0,0003\end{array}$ \\
\hline 5 & Актелик $(3,6 \%)$ & 0,15 & 0,0054 & - & 0,0054 \\
\hline
\end{tabular}

* За д.в. бинарной смеси принимается сумма д.в. эфоксена и инсектицида.

При наличии синергизма можно значительно снизить расход как ювеноида, так и фосфорорганического инсектицида. В частности, для получения эффекта, близкого к ЛК 50 , содержание ювеноида в смеси может быть в 2 раза, а инсектицида в 10 раз меньше, чем при использовании этих же препаратов в отдельности.

Таким образом, эксперименты показали, что инсектицидно-ювеноидная смесь заметно повышает активность препаратов против ТБ. Однако препаративные формы эфоксена с фосфорорганическими инсектицидами оказывают вредное влияние на защищаемое растение. При наличии синергетического эффекта имеет смысл уменьшать содержание ювеноида и инсектицида, добиваясь тем самым снижения фитотоксичности.

Для окончательного решения вопроса о перспективности совместного применения ювеноидов с инсектицидными добавками необходимы дальнейшие глубокие исследования с привлечением не только фосфорорганических инсектицидов, но и препаратов других классов.

Таблица \&

Показатели токсичности и коэффициенты синергетического действия (КСД) комбинированных препаратов

\begin{tabular}{|c|c|c|c|c|}
\hline \multirow{2}{*}{ 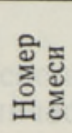 } & \multirow[b]{2}{*}{ Вид препаративной формы } & \multicolumn{2}{|c|}{ ЛК $_{50}, \%$ по д.в. } & \multirow[b]{2}{*}{ КСД** } \\
\hline & & расч.* & эксп. & \\
\hline $\begin{array}{l}2 \\
4\end{array}$ & $\begin{array}{l}\text { Эфоксен }(67,5 \%)+\text { диазинон }(3,4 \%) \\
\text { Эфоксен }(67,2 \%)+\text { актелик }(3,4 \%)\end{array}$ & $\begin{array}{l}0,0137 \\
0,0146\end{array}$ & $\begin{array}{l}0,0071 \\
0,0071\end{array}$ & $\begin{array}{l}1,9 \\
2,0\end{array}$ \\
\hline
\end{tabular}

* Ожидаемая аддитивная токсичность смеси (T):

$$
T=\frac{A+B}{(A: a)+(B: B)},
$$

где А, В - доли пестицидов в смеси; а, в - показатели токсичности препаратов, $\mathrm{JK}_{50}, \%$.

** КСД $=T_{\text {расч}} / T_{\text {эксп. Если }}$ КСД $=1-$ аддитивное действие, если КСД $>1-$ синергетическое действие, если КСД $<1-$ антагонистическое действие. 


\section{Выводы}

1. Использование против тепличной белокрылки соединений двух разных типов - эфоксена с добавлением микродоз (до $5 \%$ по д. в.) фосфорорганических инсектицидов - диазинона или актелика - вызывает синергетический эффект.

2. Гибель личинок происходит в результате токсического действия препаратов, тогда как гибель последующих стадий - пупариев и имаго - наступает в основном из-за нарушения гормонального баланса.

3. В случае синергетического эффекта можно снизить расход ювеноида в смеси в 2 раза, а инсектицида в 10 раз, по сравнению с использованием этих же препаратов в отдельности, и добиться тем самым снижения фитотоксичности.

\section{ЛИТЕ Р А Т У Р А}

1. Van de Veire, M. Potential control of the greenhouse fily Trialeurodes vaporariorum (West-Woud) by an insect growth regulator // Meded. Fac. Landbouwwet. Rijksuniv. (Gent), 1973, 38, N 3, 1167-1173.

2. Van de Veire, M., Degheele, $D$. An insect growth regulator of a potential control agent for the greenhouse whitefly // Meded. Fac. Landbouwwet. Rijksuniv. (Gent), $1974,38, \mathrm{~N} 1,255-258$.

3. Staal, G. B. Insect growth regulators with juvenile hormone activity // Ann. Rev. Entomol., 1975, N 20, 417-460.

4. Метспалу Л., Хийесаар К., Куузик А., Тээс С. Результаты применения ювеноида АЮГ-80А в борьбе с оранжерейной белокрылкой // Тез. докл. научно-произв. конф. «Пути дальнейшего совершенствования защиты растений в республиках Прибалтики и Белоруссии», ч. 1. Рига, 1983, 173-174.

5. Новикова С. А., Буров В. Н., Волкова М. А. Применение регуляторов роста и развития насекомых в борьбе с тепличной белокрылкой // Тез. докл. 5-й произв. конф. по защите растений в теплицах. Вильнюс, 1986, 58-59.

6. Попов П. В. Оценка токсического действия смесей пестицидов // Химия в сельском хоз-ве, 1976, № 11, 54-55.

Всесоюзный НИИ защиты растений

Поступила в редакцию

Ннститут химии 2/IV 1988

Академии наук Эстонской ССР

\section{S. NOVIKOVA, V. BUROV, K. LAATS, I. KUDRJAVTSEV, Tatjana LIIV}

\section{JUVENOIDIDE KASUTAMISE VOIMALUSEST KOOS MIKRODOOSIDES INSEKTITSIIDIDEGA KASVUHOONEKARILASE TORJE EFEKTIIVSUSE TOOSTMISEKS}

On uuritud koos mikrodoosides insektitsiididega kasutatava juvenoidpreparaat efokseeni môju kasvuhoonekarilasele ning näidatud, et esineb sünergismiefekt, mille tõttu juvenoidi hulk segus väheneb kaks korda, insektitsiidi oma aga kümme korda, vōrreldes nende preparaatide kasutamisega eraldi.

Madalama juvenoidi- ja insektitsiidisisaldusega preparatiivse vormi kasutamise suhtes on vajalikud edasised uuringud fototoksilisuse vähendamiseks.

\section{S. NOVIKOVA, V. BUROV, K. LAATS, I. KUDRYAVTSEV, Tatyana LIIV}

\section{USE OF JUVENOIDS WITH MICRODOSES OF INSECTICIDES TO ENHANCE GREENHOUSE WHITEFLY CONTROL}

The effect of juvenoid preparation ephoxen on greenhouse whitefly with addition of microdoses of insecticides diazinon or actelic has been investigated. It has been demonstrated that in these cases a synergistic effect occurs due to which the juvenoid application rate in the mixture decreases twice and that of insecticide ten-fold as compared to the case when these preparations are used alone.

Further study is necessary with respect to the use of the preparation form of lower juvenoid and the insecticide content to reduce phototoxicity. 